\title{
Correction to: Breast cancer classification in pathological images based on hybrid features
}

\section{Cuiru Yu ${ }^{1}$ (D) Houjin Chen ${ }^{1} \cdot$ Yanfeng $\mathrm{Li}^{1} \cdot$ Yahui Peng ${ }^{1} \cdot$ Jupeng $\mathrm{Li}^{1} \cdot$ Fan Yang ${ }^{1}$}

Published online: 9 April 2019

(C) Springer Science+Business Media, LLC, part of Springer Nature 2019

\section{Correction to: Multimedia Tools and Application \\ https://doi.org/10.1007/s11042-019-7468-9}

The article Breast cancer classification in pathological images based on hybrid features, written by Cuiru Yu, Houjin Chen, Yanfeng Li, Yahui Peng, Jupeng Li and Fan Yang, was originally published electronically on the publisher's internet portal (currently SpringerLink) on March 16, 2019 with open access.

With the author(s)' decision to step back from Open Choice, the copyright of the article changed on April 2019 to (C) Springer Science+Business Media, LLC, part of Springer Nature 2019 and the article is forthwith distributed under the terms of copyright.

The original article has been corrected.

Publisher's note Springer Nature remains neutral with regard to jurisdictional claims in published maps and institutional affiliations.

The online version of the original article can be found at https://doi.org/10.1007/s11042-019-7468-9

Yanfeng Li

yf.li@bjtu.edu.cn

1 School of Electronic Information Engineering, Beijing Jiaotong University, Beijing 100044, China 